\title{
Quantitative microstructural analysis of olivine and ringwoodite
}

TAIT, K. T. ${ }^{1,2}$, WHITE, L. F. ${ }^{1,2}$, DARLING, J. R. ${ }^{3}$, KIZOVSKI, T. V..$^{1,2}$, DunLOP, J. ${ }^{3} \&$ MOSER, D. E. ${ }^{4}$

${ }^{1}$ Department of Natural History, Royal Ontario Museum, Toronto, Canada

${ }^{2}$ Department of Earth Science, University of Toronto, Canada

${ }^{3}$ School of the Environment, Geography and Geosciences, University of Portsmouth, United Kingdom

${ }^{4}$ Western

The shock metamorphic effects on olivine have the potential to allow reconstruction of shock pressures on a range of terrestrial and meteoritic samples [1]. For example, the transformation pressure of the polymorph ringwoodite ( $>18 \mathrm{GPa}[2]$ ), allows that ringwoodite forms in a wide range of meteorites. However, it is also possible that this phase may revert to olivine during decompression and cooling and this would potentially explain the near-total absence of ringwoodite in highly shocked (e.g. martian) samples. Here, we use electron backscatter diffraction (EBSD) to analyze ringwoodite and olivine relationships in two highly shocked meteorites to yield new insights into the metamorphic pathways of these phases. Within an impact melt vein in the L6 chondrite Catherwood, polycrystalline ringwoodite is comprised of $<5 \mu \mathrm{m}$ wide, randomly oriented granules. Within one olivine grain, ringwoodite grains at the contact with the impact melt vein have transitioned to polycrystalline ringwoodite, whereas the remainder contains olivine with $<50^{\circ}$ of misorientation that we observe, interpreted to form from crystal plastic deformation. There is no crystallographic evidence for a precursor ringwoodite phase in these olivine domains. Likewise, no ringwoodite reversion textures are apparent in EBSD measurements of olivine in the highly shocked martian meteorite NWA 6342, which has experienced pressures on the order of $\sim 75 \mathrm{GPa}$ [3]. Despite extensive crystal plastic deformation and local granularization of the olivine, there are no crystallographic relationships that could be linked to a high symmetry ringwoodite precursor. Although it is likely many highly shocked meteorites reached pressure and temperature conditions consummate with ringwoodite formation, the absence of phase heritage [e.g. 5] in chondritic and martian olivine, and the spatial relationship with shock melt veins, suggests that a P-T pathway into the stability field of ringwoodite alone is not sufficient to form the polymorph, and that deformation kinetics may play a role in the transformation.

References: [1] Stoffler et al., (1991). GCA, 55, 3845-3867. [2] Kerschhofer et al., (2000). Phys Earth Planet Interiors, 121, 59-76. [3] Kizovski et al., (2019). MAPS, 54, 768-784. [5] Timms et al., (2017). EPSL, 477, 52-58. 